\title{
Fracture Parameters of Plain Concrete Beams Using ANSYS
}

\author{
Manasa Koppoju ${ }^{1}$ and T. Muralidhara Rao ${ }^{2}$ \\ 'CVR College of Engineering/Civil Engineering Department, Hyderabad, India \\ Email: koppojumanasa114@gmail.com \\ ${ }^{2} \mathrm{CVR}$ College of Engineering/Civil Engineering Department, Hyderabad, India \\ Email: tmuralidhararao@gmail.com
}

\begin{abstract}
The present paper analyses the size dependency of the fracture energy and the fracture toughness of concrete determined as per the RILEM Work-of-fracture method (WFM). Normal and high strength concrete notched beams have been modeled using the finite element software, ANSYS 12.1 to study the variation of the fracture parameters. The fracture parameters $\left(G_{F}, K_{1}\right.$ and SIF) are determined using Work of fracture method by testing geometrically similar notched Plain normal and high strength concrete $(20,30,40,50,60,70 \mathrm{MPa})$ specimens of different sizes in a size ratio of $1: 4$ with different notch depths $\left(_{0} / d=0.15,0.30\right.$ and 0.45) under three point bending through load-deflection curves. The variation of both the fracture energy, fracture toughness and the stress intensity factor as a function of the specimen size and notch depth was determined using RILEM Work-of-fracture method. Fracture energy, fracture toughness and stress intensity factor calculated using Workof-fracture method are increasing with the increase in size of specimen and decreasing with the increasing notch depth ratios.
\end{abstract}

Index Terms - Crack length, Fracture energy, Fracture toughness, Stress Intensity factor, Brittleness, Peak load, Finite element analysis, ANSYS.

\section{INTRODUCTION}

Concrete, the highest consumed material in the construction field endowed with the inherent qualities of easy mouldability to the desired architectural shape and finish, high resistance to fire, easy and economically available raw ingredients with high compressive strength. Cracking in any material occurs when the principal tensile stress reaches the tensile strength of the material at that location. The study of the conditions around the crack tip is called fracture mechanics. None of the conventional strength theories like elastic or plastic theory describes how the cracks propagate in a structure. The safety and durability of concrete structures is significantly influenced by the cracking behavior of concrete. Therefore, concrete structures are mainly designed to satisfy two criteria namely, safety and serviceability. The evaluation of adequate margin of safety of concrete structures against failure is assured by the accurate prediction of ultimate load and the complete load-deformation behavior or momentcurvature response. Based on the tensile stress-deformation response, most engineering materials can be categorized into three main classes:

Brittle: stress suddenly drops to zero when a brittle material fractures.

Ductile: stress remains constant when a ductile material yields.
Quasi-brittle: It is characterized by a gradually decreasing stress after the peak stress.

\section{A. Modes of Fracture}

According to the mode of failure, fracture behaviour is classified into three categories. The three basic modes of failure are presented in Fig1.1. Mode I failure is known as the Opening mode failure. In this mode, the displacement of the crack surfaces is perpendicular to the plane of the crack. Mode II failure is known as the Sliding mode or Planar Shear mode failure. In this mode, the displacement of the crack surfaces is in the plane of the crack and perpendicular to the leading edge of the crack. The third basic mode is known as the Tearing mode or Anti-Plane Shear mode failure. In this mode, the displacement is in the plane of the crack and parallel to the leading edge of the crack. In practice, it is difficult to develop pure mode II or mode III fractures in concrete structures. Thus, besides pure mode I, mode of failure is often a combination of basic modes which is called mixed mode.

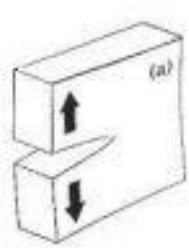

(a) Mode-1

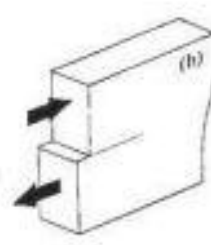

(b) Mode-II

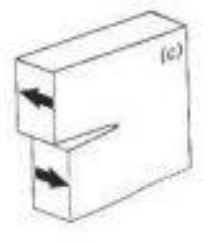

(c) Mode-III
Figure 1. Modes of Fracture

\section{B. Stress Intensity Factor $K_{i}$}

The stress intensity factor is utilized as a part of fracture mechanics to predict the stress state ("stress intensity") close to the tip of a notch brought about by a remote load or residual stresses. It is a hypothetical construct normally applied to a homogeneous, linear elastic material and is helpful for giving a failure criterion for brittle materials, and is a basic technique and is a critical technique in the discipline of damage tolerance.. The idea can likewise be connected to materials that display little scale yielding at a notch tip.

\section{Fracture Energy $G_{f}$}

The strain energy discharge rate (or essentially energy discharge rate) is the energy dispersed during fracture per unit of newly created crack surface region. The energy discharge rate failure criterion expresses that a notch will grow when the accessible energy discharge rate $\mathrm{G}$ is greater 
than or equivalent to a basic worth $\mathrm{Gc}$. The amount $\mathrm{Gc}$ is the fracture energy.

D. Non-Linear Fracture Parameters

Fracture Energy usingWork-Of-Fracture Method. Based on a measured load-deflection curve of a fracture specimen, typically a three point bend beam (including the effect of its own weight), the work of load P on the load-point displacement $\delta$ in RILEM method is calculated as $W_{f}=\int P d \delta$.

Figure 1.shows a typical three point bend test set up for the determination of fracture parameters using RILEM Work-of-Fracture method.

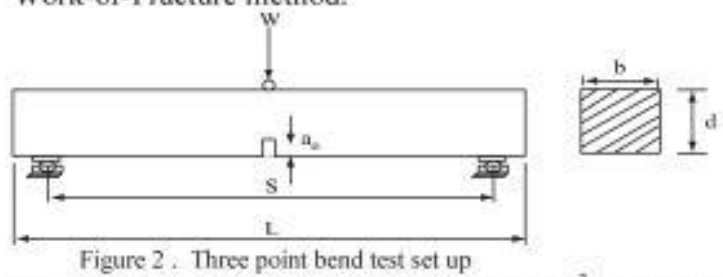

The fracture energy according to the RILEM ${ }^{3}$ definition, $W_{f}$ $\mathrm{G}_{\mathrm{F}}\left(a_{0}, \mathrm{~d}\right)=\frac{W f}{B\left[\left(1-\alpha_{0}\right) d\right]} \quad$ Where $\alpha_{0}=\left(\frac{a_{0}}{d}\right)$

E. Fracture Toughness $K_{R C}$

Fracture toughness is the property which portrays the capacity of the material containing a crack to resist fracture. If a material has high fracture toughness it will presumably undergo ductile fracture. For two dimensional issues (plane stress, plane strain, anti-plane shear) including crack that move in a straight path, the Mode I fracture toughness is identified with the energy release rate, $\mathrm{G}_{\mathrm{f}}$ by

$\mathrm{K}_{\mathrm{IC}}=\sqrt{G f X E}$

\section{SAMPLE LOAD CALCULATION}

The most extreme load and Fracture Load are observed to appear as something else and an exceptional quality for the fracture load is obtained.

The peck load carried by $\mathrm{M} 20$ grade concrete having beam size of $100 \mathrm{~mm} \times 150 \mathrm{~mm} \& \mathrm{a} / \mathrm{D}: 0.15$

BendingEquation: $\frac{M}{I}=\frac{\sigma c b c}{y}=\frac{E}{R}$

$\sigma c b c=\frac{f c k}{3} \frac{20}{3}=6.67 \mathrm{~N} / \mathrm{mm}^{2}$

For simply supported beams, the maximum bending moment is

$\mathrm{M}=\frac{w \ell}{4}=\frac{w X 1050}{4}$

$\mathrm{M}=262.5 \mathrm{w}$

Where width of beam is $=100 \mathrm{~mm}$

Effective depth, $\mathrm{d}=150-22.5=127.5 \mathrm{~mm}$

Moment of inertia

$\mathrm{I}=\frac{100 X(127.5) 3}{12}=17.272 \times 10^{6} \mathrm{~mm} 4$

Depth of Neutral axis $y=\frac{127.5}{2}=63.75 \mathrm{~mm}$

$\sigma c b c=\frac{M}{\ell} x y=\frac{262.5 w}{17.272 \times 10^{\circ} 6} \times 63.75=6.67 \mathrm{MPa}$
Live Load, $w=6884.28 \mathrm{~N}$

Self weight of Beam:

$0.1 \times 0.15 \times 25=0.36 \mathrm{kN} / \mathrm{m}=360 \mathrm{~N} / \mathrm{m}$

Dead Load $w_{D}=378 \mathrm{~N}$

Total Load $=\mathrm{w}+\mathrm{w}_{\mathrm{D}}=7262.28 \mathrm{~N}$

The Peak load values of various grades of concrete $(\mathrm{M} 20-\mathrm{M} 70)$ with different $\mathrm{a} / \mathrm{D}$ ratiosand different beam sizes are calculated and tabulated in the Table $\mathrm{L}$.

TABLE I.

PEAK LOAD VALUES FOR BEAMS OF DIFFERENT SIZES, GRADES AND NOTCH-DEPTH RATIOS

\begin{tabular}{|c|c|c|c|}
\hline $\begin{array}{l}\text { Grade of } \\
\text { concrete }\end{array}$ & $\begin{array}{l}\text { Size of Beam } \\
(\mathrm{mm} \times \mathrm{mm})\end{array}$ & $\mathrm{a} D$ & Peak Load N \\
\hline \multirow{9}{*}{$\mathrm{M} 20$} & \multirow{3}{*}{$100 \times 75$} & 0.15 & 3536.643 \\
\hline & & 0.3 & 2428.88 \\
\hline & & 0.45 & 454.79 \\
\hline & \multirow{3}{*}{$100 \times 150$} & 0.15 & 7262.28 \\
\hline & & 0.3 & 5046.57 \\
\hline & & 0.45 & 3260.209 \\
\hline & \multirow{3}{*}{$100 \times 300$} & 0.15 & 15280.77 \\
\hline & & 0.3 & 10850.1 \\
\hline & & 0.45 & 5764.11 \\
\hline \multirow{9}{*}{ M30 } & \multirow{3}{*}{$100 \times 75$} & 0.15 & 5255.13 \\
\hline & & 0.3 & 3594.327 \\
\hline & & 0.45 & 634.6788 \\
\hline & \multirow{3}{*}{$100 \times 150$} & 0.15 & 10699.27 \\
\hline & & 0.3 & 7377.365 \\
\hline & & 0.45 & 4699.154 \\
\hline & \multirow{3}{*}{$100 \times 300$} & 0.15 & 22154.84 \\
\hline & & 0.3 & 15512 \\
\hline & & 0.45 & 10154.77 \\
\hline \multirow{9}{*}{ M40 } & \multirow{3}{*}{$100 \times 75$} & 0.15 & 6975.346 \\
\hline & & 0.3 & 4760.936 \\
\hline & & 0.45 & 814.7379 \\
\hline & \multirow{3}{*}{$100 \times 150$} & 0.15 & 14139.69 \\
\hline & & 0.3 & 9710.487 \\
\hline & & 0.45 & 6139.539 \\
\hline & \multirow{3}{*}{$100 \times 300$} & 0.15 & 29035.78 \\
\hline & & 0.3 & 20178.67 \\
\hline & & 0.45 & 13034.46 \\
\hline \multirow{9}{*}{ M50 } & \multirow{3}{*}{$100 \times 75$} & 0.15 & 8695.558 \\
\hline & & 0.3 & 5927.546 \\
\hline & & 0.45 & 994.79 \\
\hline & \multirow{3}{*}{$100 \times 150$} & 0.15 & 17580.52 \\
\hline & & 0.3 & 12043.61 \\
\hline & & 0.45 & 7579.92 \\
\hline & \multirow{3}{*}{$100 \times 300$} & 0.15 & 35916.73 \\
\hline & & 0.3 & 24845.33 \\
\hline & & 0.45 & 15915.08 \\
\hline \multirow{9}{*}{ M60 } & \multirow{3}{*}{$100 \times 75$} & 0.15 & 10415.77 \\
\hline & & 0.3 & 7094.155 \\
\hline & & 0.45 & 1174.856 \\
\hline & \multirow{3}{*}{$100 \times 150$} & 0.15 & 21020.54 \\
\hline & & 0,3 & 14376.73 \\
\hline & & 0.45 & 9020.309 \\
\hline & \multirow{3}{*}{$100 \times 300$} & 0.15 & 42797.68 \\
\hline & & 0.3 & 29512 \\
\hline & & 0.45 & 1879.69 \\
\hline & & 0.15 & 12135.98 \\
\hline & $100 \times 75$ & 0.3 & 8260.765 \\
\hline & & 0.45 & 1354.916 \\
\hline & & 0.15 & 24460.96 \\
\hline M70 & $100 \times 150$ & 0.3 & 16426,35 \\
\hline & & 0.45 & 10460,69 \\
\hline & & 0.15 & 49678.62 \\
\hline & $100 \times 300$ & 0.3 & 34178.67 \\
\hline & & 0.45 & 21676.31 \\
\hline
\end{tabular}




\section{FINITE ELEMENT MODELIING}

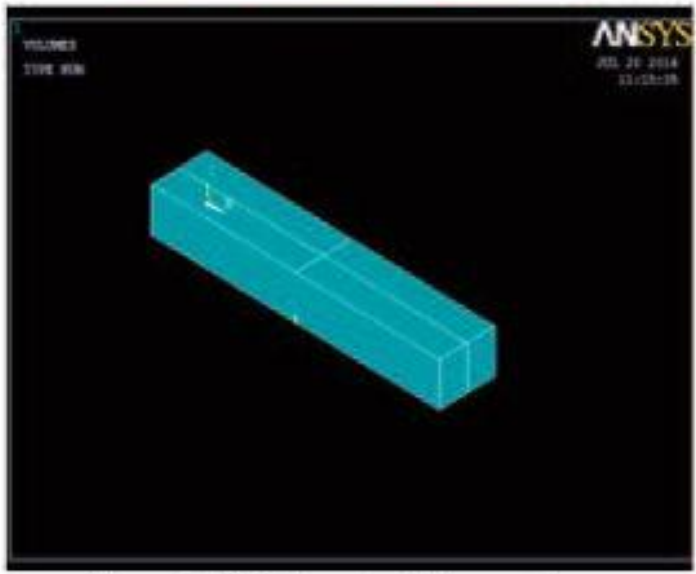

Figure 3. 3D Modeling of notched concrete beam

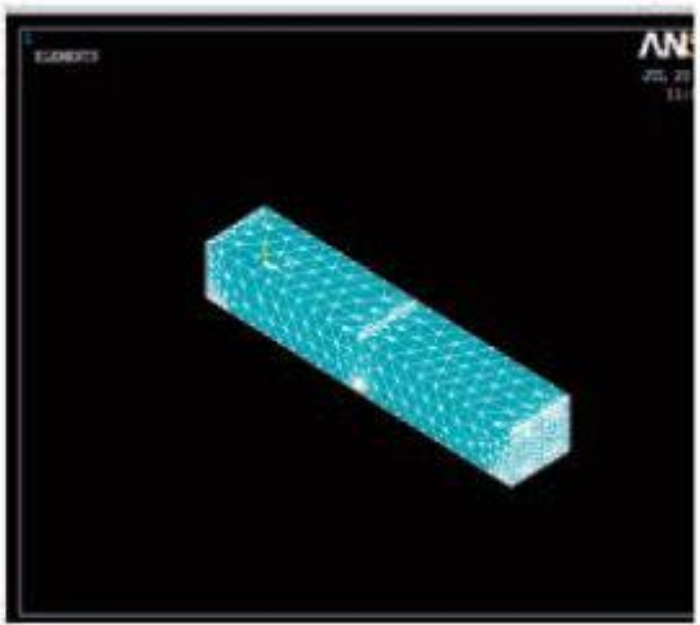

Figure 4, 3D Meshing of notched concrete beam

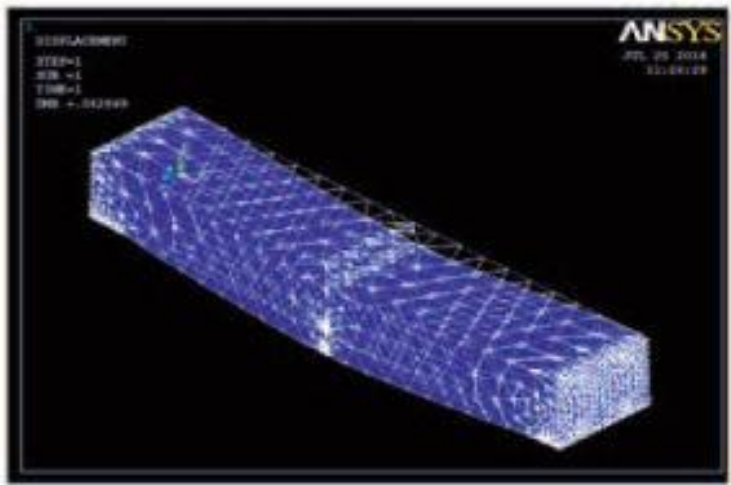

Figure 5. Deformed shape of notched concrete beam

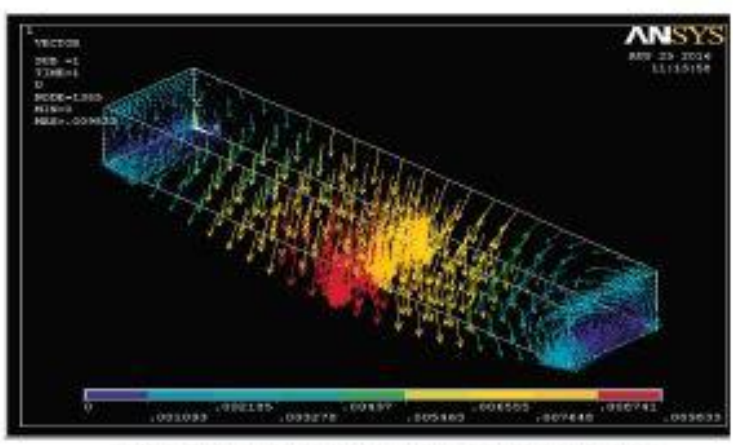

Figure .6. Vectorload Plot of notchod concrete beam

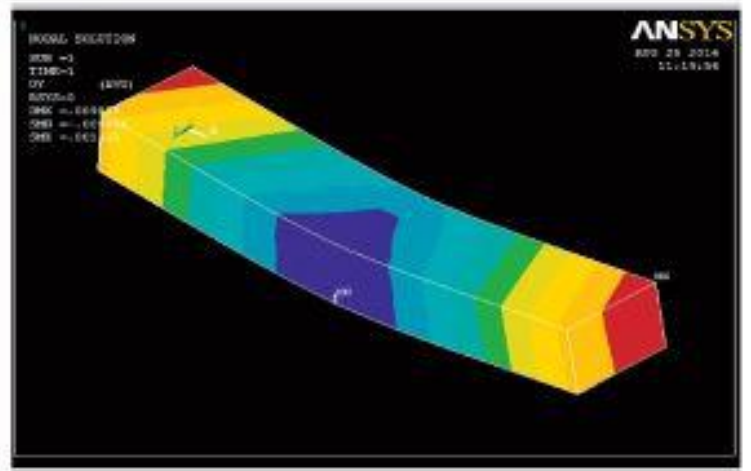

Figure 7. Stress variation over the notched concrete beam

\section{ANALYSIS OF NOTCHED CONCRETE BEAMS}

The load-deflection figure shows a different deformation and behavior under the loads for beams, thus beam specimens had been made with two variables (notch depth/beam depth ratio, and Concrete grade) were tested to the ultimate load capacity so as to research deflection behavior in this study.

For particular depth, notch depth-beam depth ratio, The Stress intensity factor is observed to be increasing with the increase in the load and this stress intensity factor determined at crack tip. The following table shows the test results of the beams.

\begin{tabular}{|c|c|c|c|c|}
\hline $\begin{array}{c}\text { Grade } \\
\text { of } \\
\text { concrete }\end{array}$ & $\begin{array}{l}\text { Size of } \\
\text { Beam } \\
\text { (mem } x \text { mmin }\end{array}$ & $\mathrm{a} / \mathrm{D}$ & $\underset{\mathrm{mm}}{\text { Deflection }}$ & $\begin{array}{c}\text { Stress } \\
\text { intensity } \\
\text { factor } N \text { mm }\end{array}$ \\
\hline \multirow{9}{*}{ M20 } & \multirow{3}{*}{$100 \times 75$} & 0.15 & 0.062869 & 4.77808 \\
\hline & & 0.3 & 0.047178 & 3.00501 \\
\hline & & 0.45 & 0.009912 & 0.581767 \\
\hline & \multirow{3}{*}{$100 \times 150$} & 0.15 & 0.10838 & 5.06743 \\
\hline & & 0.3 & 0.083037 & 3.30101 \\
\hline & & 0.45 & 0.083037 & 1.89274 \\
\hline & \multirow{3}{*}{$100 \times 300$} & 0.15 & 0.205183 & 6.42495 \\
\hline & & 0.3 & 0.1600362 & 4,57469 \\
\hline & & 0.45 & 0.118737 & 2.22868 \\
\hline \multirow{8}{*}{ M30 } & \multirow{3}{*}{$100 \times 75$} & 0.15 & 0.076864 & 7.14012 \\
\hline & & 0.3 & 0.057006 & 4,47298 \\
\hline & & 0.45 & 0.011293 & 0.678518 \\
\hline & \multirow{3}{*}{$100 \times 150$} & 0.15 & 0.130372 & 6.57468 \\
\hline & & 0.3 & 0.099113 & 5.41035 \\
\hline & & 0.45 & 0.070993 & 3.05666 \\
\hline & \multirow[b]{2}{*}{$100 \times 300$} & 0.15 & 0.242896 & 6.09492 \\
\hline & & 0.3 & 0.188195 & 5.328 \\
\hline
\end{tabular}




\begin{tabular}{|c|c|c|c|c|}
\hline $\begin{array}{c}\text { Grade } \\
\text { of } \\
\text { concrete }\end{array}$ & $\begin{array}{l}\text { Size of } \\
\text { Beam } \\
(\operatorname{mim} \times \mathrm{mm})\end{array}$ & $\mathrm{a} / \mathrm{D}$ & Deflection & $\begin{array}{c}\text { Stress } \\
\text { intensity } \\
\text { factor } \mathrm{N} / \mathrm{mm}^{2}\end{array}$ \\
\hline & & 0.45 & 0.115158 & 3,404411 \\
\hline \multirow{9}{*}{ M40 } & \multirow{3}{*}{$100 \times 75$} & 0.15 & 0.088355 & 9.42384 \\
\hline & & 0.3 & 0.065392 & 5.65244 \\
\hline & & 0.45 & 0.012554 & 0.871014 \\
\hline & \multirow{3}{*}{$100 \times 150$} & 0.15 & 0.149211 & 10.536 \\
\hline & & 0.3 & 0.11298 & 8.22713 \\
\hline & & 0.45 & 0.080327 & 3.99358 \\
\hline & \multirow{3}{*}{$100 \times 300$} & 0.15 & 0.275686 & 11.3609 \\
\hline & & 0.3 & 0.210886 & 8.95672 \\
\hline & & 0.45 & 0.150406 & 4.36984 \\
\hline \multirow{9}{*}{ M50 } & \multirow{3}{*}{$100 \times 75$} & 0.15 & 0.096178 & 12,736 \\
\hline & & 0.3 & 0.072495 & 7.37656 \\
\hline & & 0.45 & 0.013675 & 3.1247 \\
\hline & \multirow{3}{*}{$100 \times 150$} & 0.15 & 0.183628 & 12.2141 \\
\hline & & 0.3 & 0.125368 & 7.94811 \\
\hline & & 0.45 & 0.087948 & 4.40057 \\
\hline & \multirow{3}{*}{$100 \times 300$} & 0.15 & 0.30523 & 13.6341 \\
\hline & & 0.3 & 0.231193 & 9.36027 \\
\hline & & 0.45 & 0.164004 & 5.16299 \\
\hline \multirow{9}{*}{$\mathrm{M} 60$} & \multirow{3}{*}{$100 \times 75$} & 0.15 & 0.1069 & 13.2991 \\
\hline & & 0.3 & 0.079203 & 8.82835 \\
\hline & & 0.45 & 0.014744 & 5.12879 \\
\hline & \multirow{3}{*}{$100 \times 150$} & 0.15 & 0.180488 & 129171 \\
\hline & & 0.3 & 0.136615 & 9,48784 \\
\hline & & 0.45 & 0.10416 & 5.2368 \\
\hline & \multirow{3}{*}{$100 \times 300$} & 0.15 & 0.33284 & 16.1583 \\
\hline & & 0.3 & 0.250691 & 11.1184 \\
\hline & & 0.45 & 0.173231 & 5.75713 \\
\hline \multirow{9}{*}{ M70 } & \multirow{3}{*}{$100 \times 75$} & 0.15 & 0.115315 & 15.4955 \\
\hline & & 0.3 & 0.092228 & 10.2801 \\
\hline & & 0.45 & 0.015742 & 4.1456 \\
\hline & \multirow{3}{*}{$100 \times 150$} & 0.15 & 0.194449 & 16.0312 \\
\hline & & 0.3 & 0.144513 & 10.8405 \\
\hline & & 0.45 & 0.102579 & 6.07302 \\
\hline & \multirow{3}{*}{$100 \times 300$} & 0.15 & 0.357694 & 18.7562 \\
\hline & & 0.3 & 0.288795 & 128765 \\
\hline & & 0.45 & 0.189231 & 6.63946 \\
\hline
\end{tabular}

TABLE II

DEFLECTION, STRESS INTENSITY FACTOR FOR BEAMS OF DIFFERENT SIZES, GRADES AND NOTCH-DEPTH RATIOS

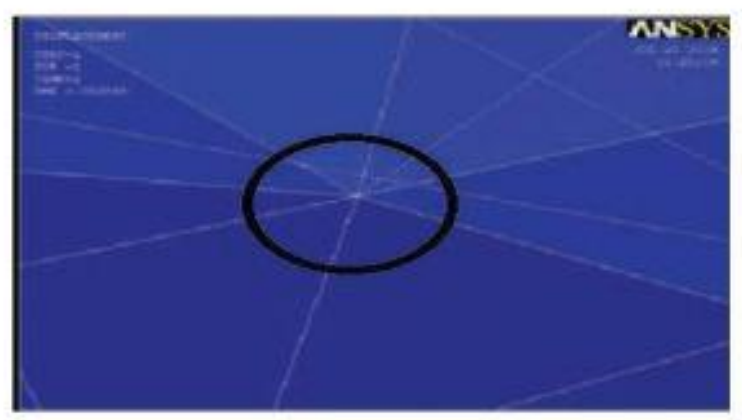

Figure 8. Deflection at point of application of load

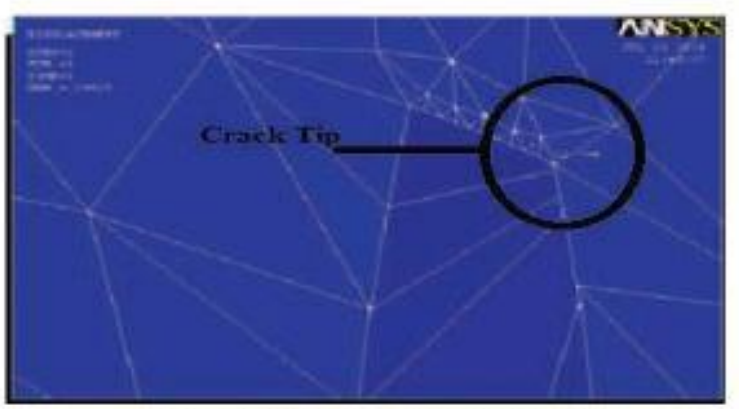

Figure 9. Stress intensity factor at erack tip

\section{RESULTS ANALYSIS}

\section{A. Peak Load Vs Notch-depth Ratio}

When the grade of concrete and the size of the beam is constant, then the peak load and the deflection were found to be decreasing with the increase in the notch depth ratios. This is due to the increase in the brittleness of the member, in other words, the increase in the crack length in a member makes it to behave in a brittle manner. The following graphs shows relation between peak load and notch - depth ratio.

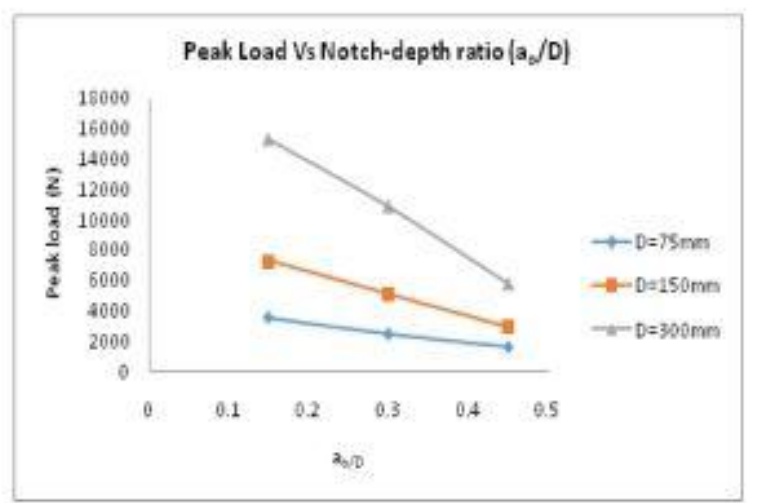

Figure10. Peak Load vs Notch-depth ratio (M20 Concrete)

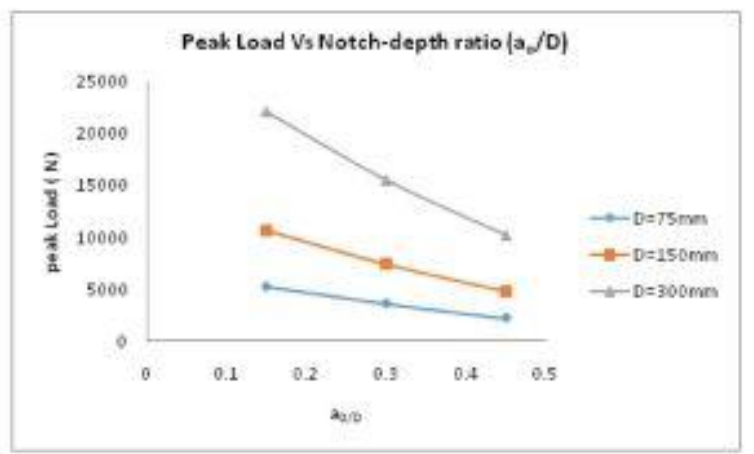

Figure 11. Peak Load veNotch-depth ratio (M30 Concrete) 


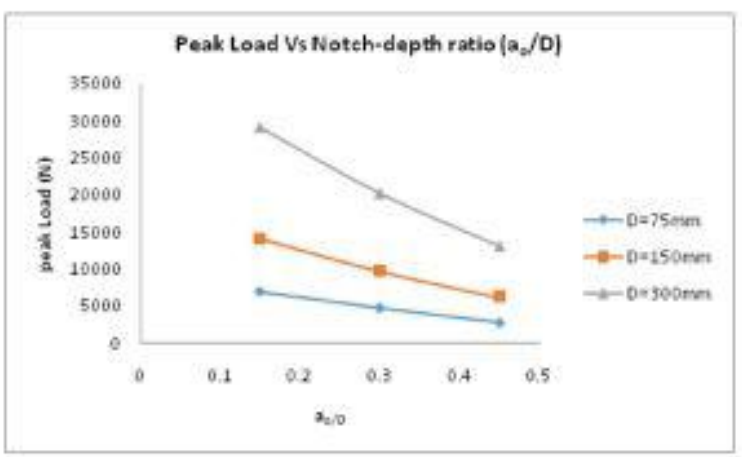

Figure 12. Peak Load vgNotch-depth ratio (M40 Concrete)

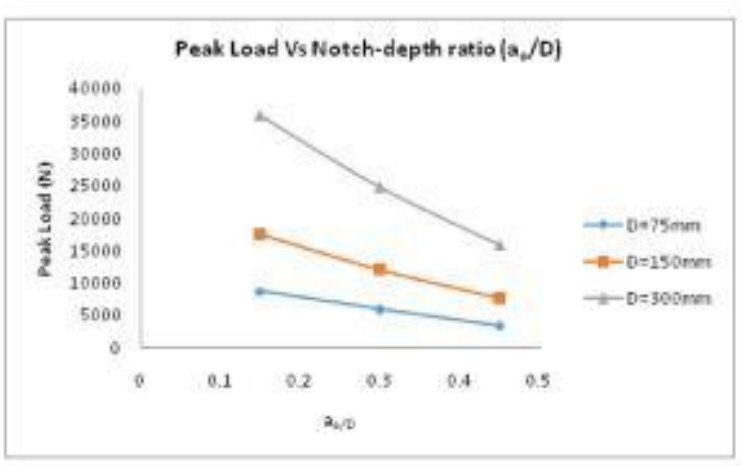

Figure 13. Peak Load vsNotch-depth ratio (M50 Concrete)

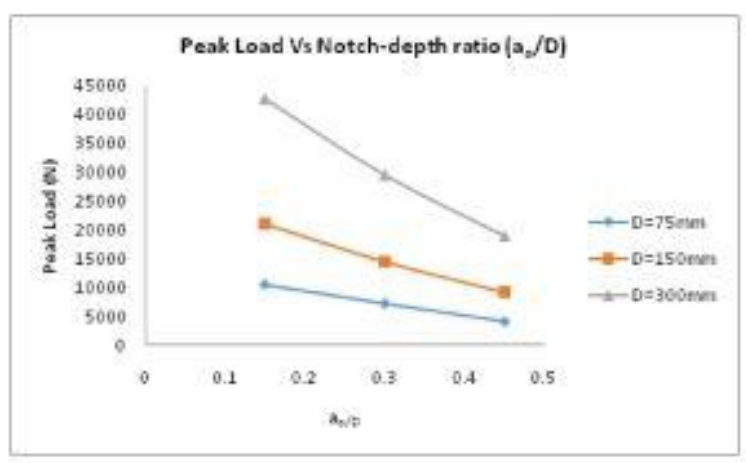

Figure 14. Peak Load vy Notch-depth ratio (M60 Concrete)

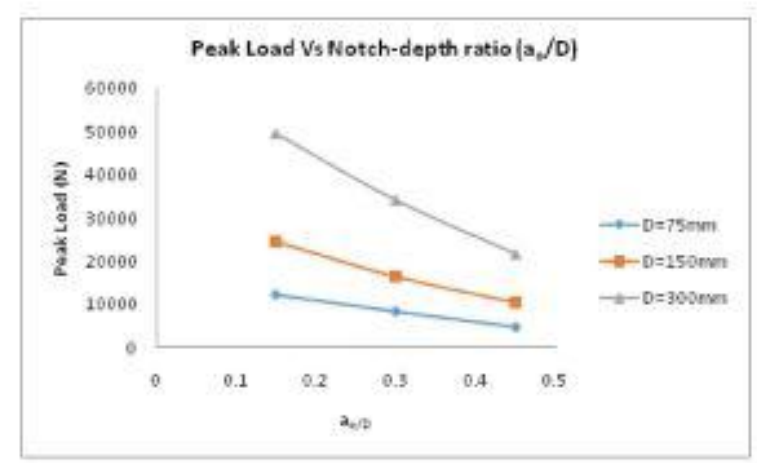

Figure 15. Peak Load visotch-depth ratio (M70 Concrete)
B. Depth Vs Fracture Energy $(G \phi$

From the following graphs it is clear that in a particular notch depth-beam depth ratio, the fracture energy is observed to be increasing with the increase in the beam depth. This is due to the increase in the depth of uncracked ligament which has enhanced the load resisting capacity and hence the fracture energy of the larger depth beams. Same trend was observed with the increase in the notch depth to beam depth ratio. Similar trend was observed in all the higher grades of concrete (M30, M40, M50, M60, M70)

TABLE III

FRACTURE ENERGY FOR BEAMS OF DIFFERENT SIZES. GRADES AND NOTCH-DEPTH RATIOS

\begin{tabular}{|c|c|c|c|}
\hline $\begin{array}{l}\text { Grade of } \\
\text { concrete }\end{array}$ & $\begin{array}{l}\text { Size of Beam } \\
(\mathrm{mm} \times \mathrm{mm})\end{array}$ & $\mathrm{a} / \mathrm{D}$ & $\begin{array}{c}\text { Fracture } \\
\text { Energy (G) } \\
\mathrm{N}-\mathrm{mm}\end{array}$ \\
\hline \multirow{9}{*}{ M20 } & \multirow{3}{*}{$100 \times 75$} & 0.15 & 118,9005 \\
\hline & & 0.3 & 61.4389 \\
\hline & & 0.45 & 2.253866 \\
\hline & \multirow{3}{*}{$100 \times 150$} & 0.15 & 413.7122 \\
\hline & & 0.3 & 179.7514 \\
\hline & & 0.45 & 118.641 \\
\hline & \multirow{3}{*}{$100 \times 300$} & 0.15 & 1590.953 \\
\hline & & 0.3 & 874.1657 \\
\hline & & 0.45 & 378.2803 \\
\hline \multirow{9}{*}{ M30 } & \multirow{3}{*}{$100 \times 75$} & 0.15 & 174.8352 \\
\hline & & 0.3 & 107.4548 \\
\hline & & 0.45 & 3.457815 \\
\hline & \multirow{3}{*}{$100 \times 150$} & 0.15 & 720.9258 \\
\hline & & 0.3 & 382.877 \\
\hline & & 0.45 & 169.2044 \\
\hline & \multirow{3}{*}{$100 \times 300$} & 0.15 & 2698.787 \\
\hline & & 0.3 & 1278.975 \\
\hline & & 0.45 & 599.3161 \\
\hline \multirow{9}{*}{ M40 } & \multirow{3}{*}{$100 \times 75$} & 0.15 & 283.4675 \\
\hline & & 0.3 & 160.6794 \\
\hline & & 0.45 & 5.153569 \\
\hline & \multirow{3}{*}{$100 \times 150$} & 0.15 & 1153.086 \\
\hline & & 0.3 & 587.6143 \\
\hline & & 0.45 & 242.7794 \\
\hline & \multirow{3}{*}{$100 \times 300$} & 0.15 & 3609.718 \\
\hline & & 0.3 & 1858.153 \\
\hline & & 0.45 & 1149.008 \\
\hline $\begin{array}{l}\text { Grade of } \\
\text { concrete }\end{array}$ & $\begin{array}{l}\text { Size of Beam } \\
(\mathrm{mm} \times \mathrm{mm})\end{array}$ & $\mathrm{a} / \mathrm{D}$ & $\begin{array}{c}\text { Fracture } \\
\text { Energy }\left(\mathrm{G}_{f}\right) \\
\text { N-mm }\end{array}$ \\
\hline \multirow{9}{*}{ M50 } & \multirow{3}{*}{$100 \times 75$} & 0.15 & 430.9933 \\
\hline & & 0.3 & 214.858 \\
\hline & & 0,45 & 7.299549 \\
\hline & \multirow{3}{*}{$100 \times 150$} & 0.15 & 1712.186 \\
\hline & & 0.3 & 754.939 \\
\hline & & 0.45 & 333.6196 \\
\hline & \multirow{3}{*}{$100 \times 300$} & 0.15 & 5481.438 \\
\hline & & 0.3 & 2894.537 \\
\hline & & 0.45 & 1304.962 \\
\hline \multirow{9}{*}{ M60 } & \multirow{3}{*}{$100 \times 75$} & 0.15 & 556.7235 \\
\hline & & 0.3 & 280.9394 \\
\hline & & 0.45 & 8.660802 \\
\hline & \multirow{3}{*}{$100 \times 150$} & 0.15 & 1896.978 \\
\hline & & 0.3 & 982.0472 \\
\hline & & 0,45 & 500.306 \\
\hline & \multirow{3}{*}{$100 \times 300$} & 0.15 & 7122.385 \\
\hline & & 0.3 & 3699.201 \\
\hline & & 0.45 & 1665.591 \\
\hline
\end{tabular}




\begin{tabular}{|c|c|c|c|}
\hline \multirow{4}{*}{$100 \times 75$} & 0.15 & 699.7285 \\
\cline { 3 - 4 } & & 0.3 & 380.9375 \\
\cline { 3 - 4 } & & 0.45 & 10.66446 \\
\hline \multirow{3}{*}{ M70 } & \multirow{3}{*}{$100 \times 150$} & 0.15 & 2378.209 \\
\cline { 3 - 4 } & & 0.3 & 1186.913 \\
\cline { 3 - 4 } & & 0.45 & 536.5238 \\
\hline \multirow{3}{*}{$100 \times 300$} & 0.15 & 8880.893 \\
\cline { 3 - 4 } & & 0.3 & 5235.318 \\
\cline { 3 - 4 } & & 0.45 & 2070.237 \\
\hline
\end{tabular}

\section{Fracture Energy Vs Notch Depth}

Increase in the notch ratio $(\mathrm{a} / \mathrm{D})$ increases the brittleness of the member. In other words, increase in crack length in a structure pushes the structure to behave in a brittle manner. It indicates that the increase in notch depth ratio decreases the fracture energy. In other words, increase in crack length of a structure requires less fracture energy for extending the crack. A decrease in fracture energy for crack extension indicates the brittleness of the structure.

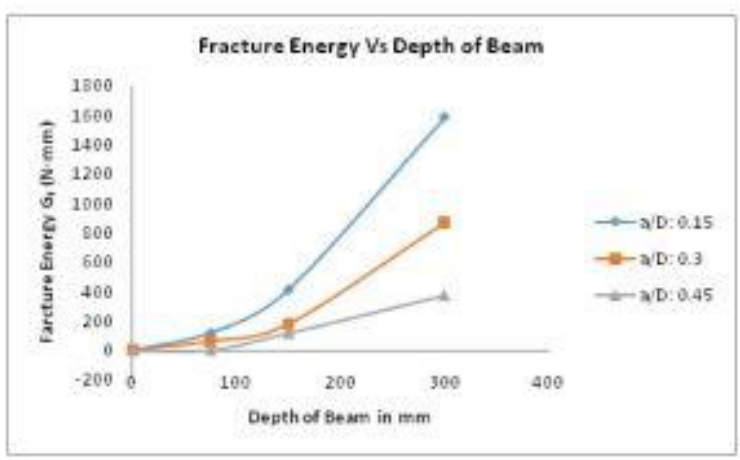

Figure 16. Fracture Energy Vs Depth of Beam (M20 concrete)

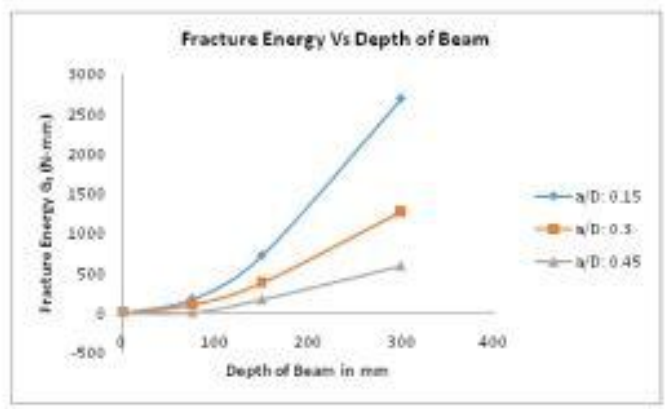

Figure 17. Fracture Energy Vs Depth of Beam (M30 concrete)

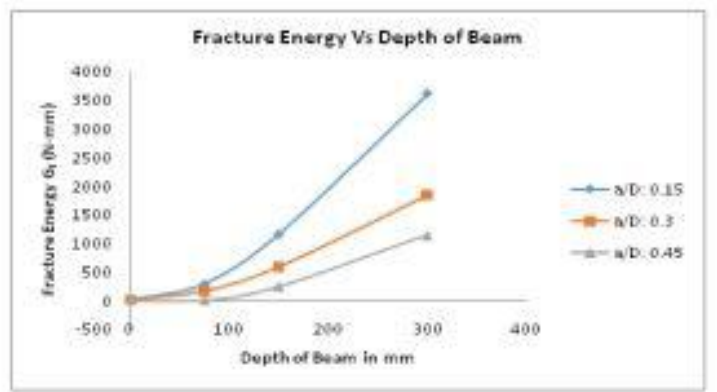

Figure 18. Fracture Energy Vs Depth of Beam (M40 concrete)

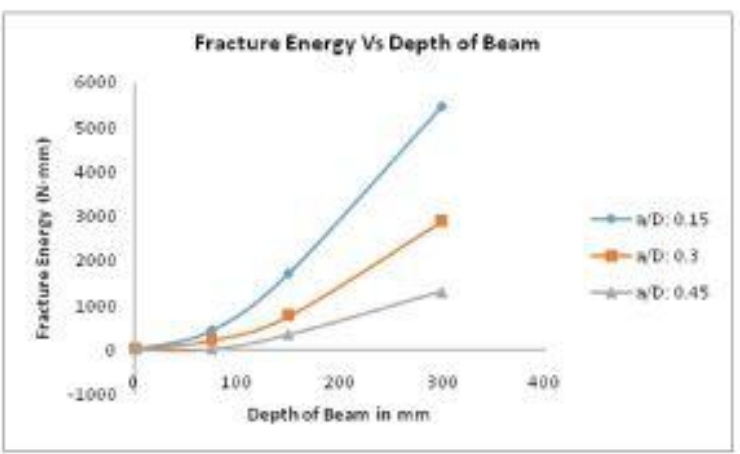

Figure 19. Fracture Energy Vs Depth of Beam (M50 concrete)

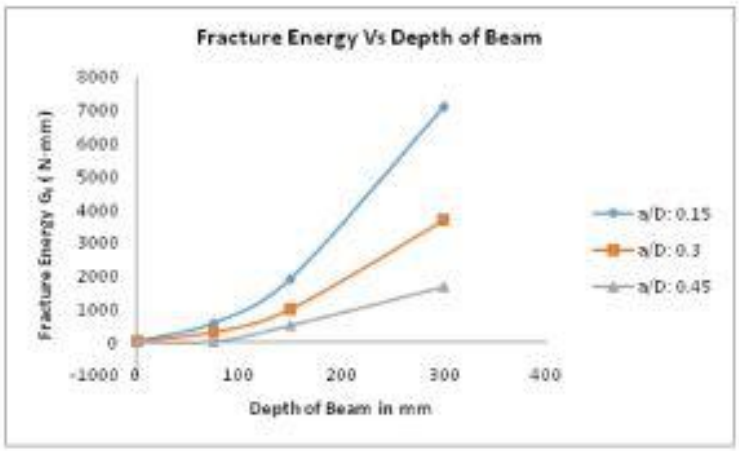

Figure 20. Fracture Energy Vs Depth of Beam (M60 concrete)

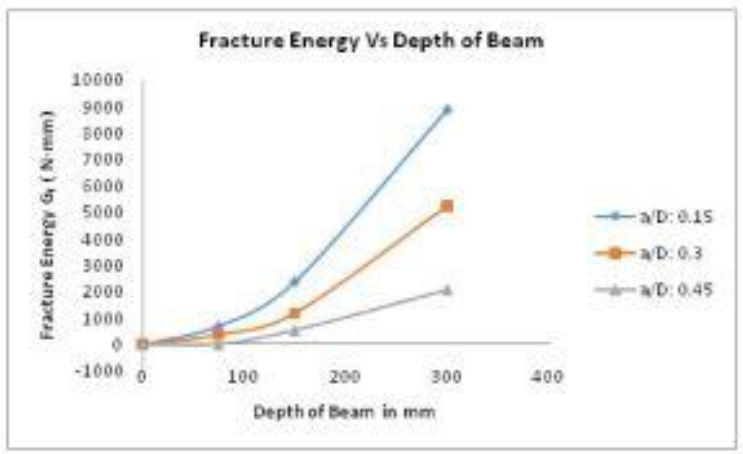

Figure 21. Fracture Energy Vs Depth of Beam (M70 concrete)

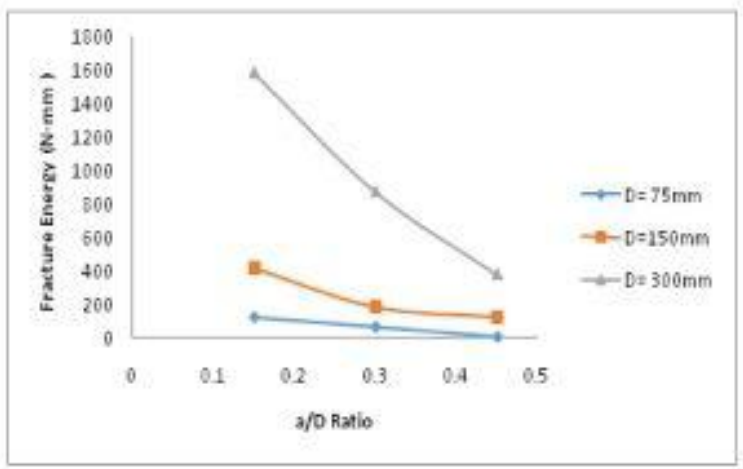

Figure 22. Fracture Energy Vs Notch depth (M20 concrete) 


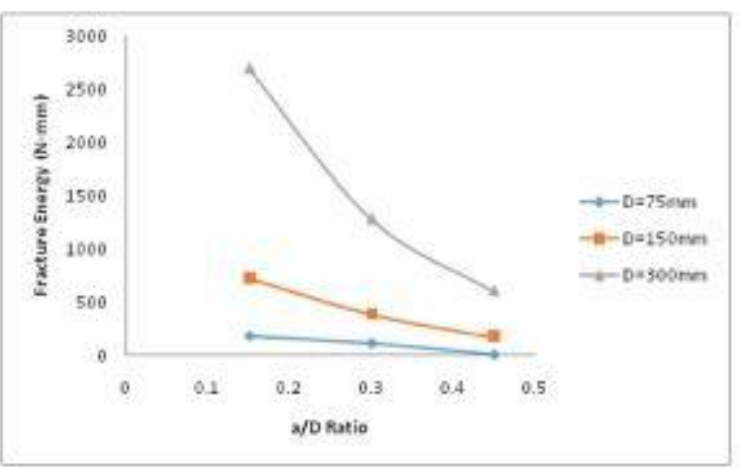

Figure 23. Fracture Energy Vs Notch depth (M30 concrete)

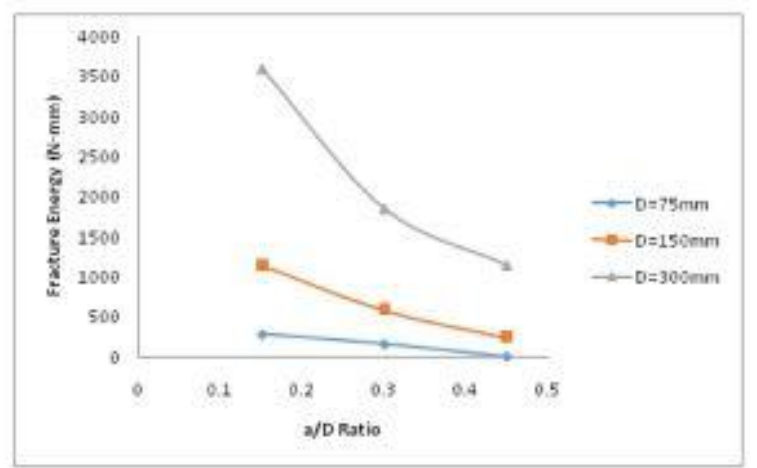

Figure 24. Fracture Energy Vs Notch depth (M40 coscrete)

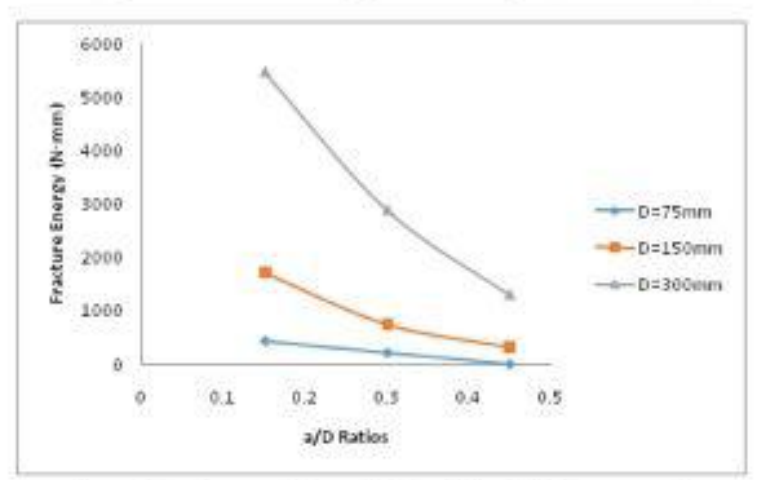

Figure 25. Fracture Energy Vs Notch depth (M50 concrete)

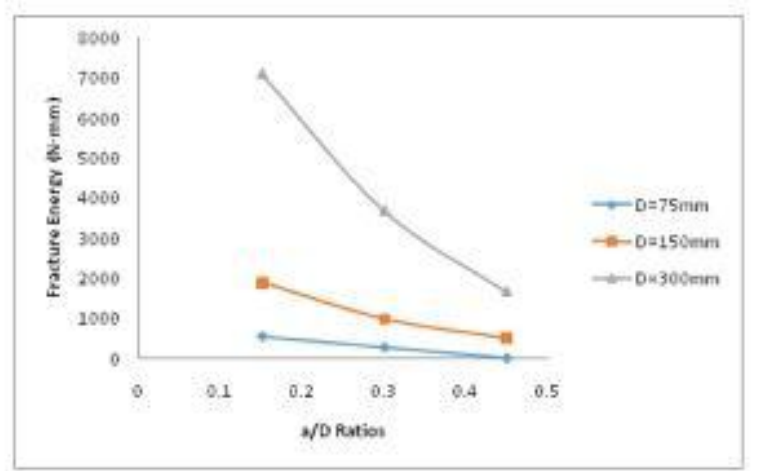

Figure 26. Fracture Energy Vs Notch depth (M60 concrete)

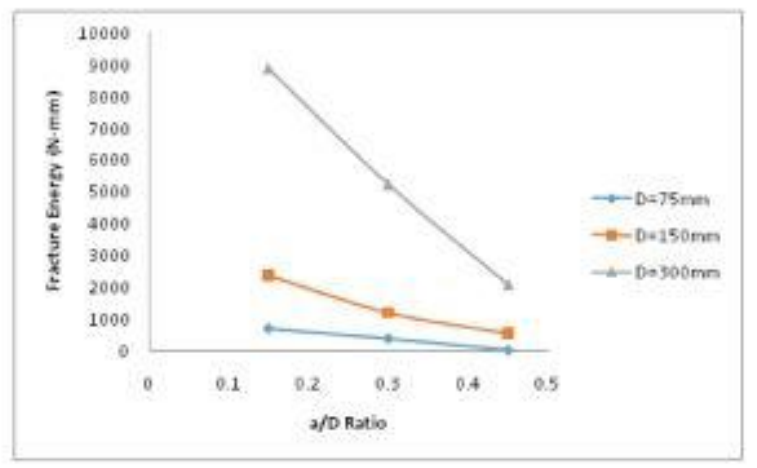

Figure 27. Fracture Energy Vs Notch depth (M70 concrete)

\section{Peak Load Vs Depth of Beam}

From the following graphs it is clear that in a particular notch depth to beam depth ratio, the Load carrying capacity is observed to be decreasing with the increase in the notch depth to beam depth ratio. If notch depth to beam depth increased the depth of uncracked ligament portion will be decreased so stiffness of member will be reduced. So load carrying capacity will gradually decrease. Same trend was observed with the increase in the notch depth to beam depth ratio. Similar trend was observed in all the higher grades of concrete (M30, M40, M50, M60, M70)

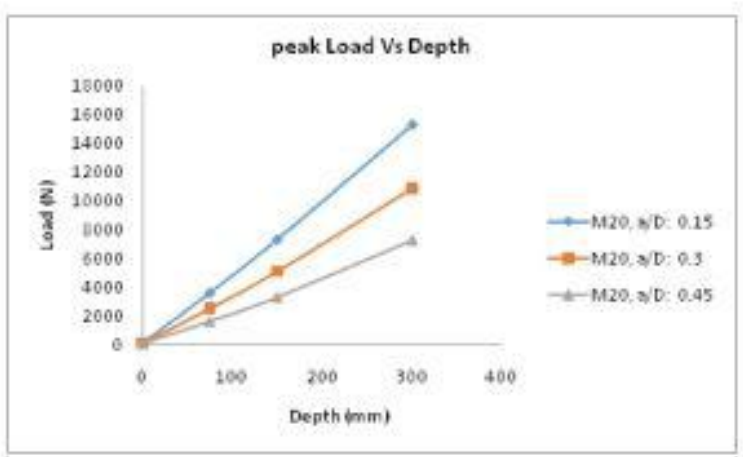

Figure 28. Peak Load Vs Depth (M20 Concrete)

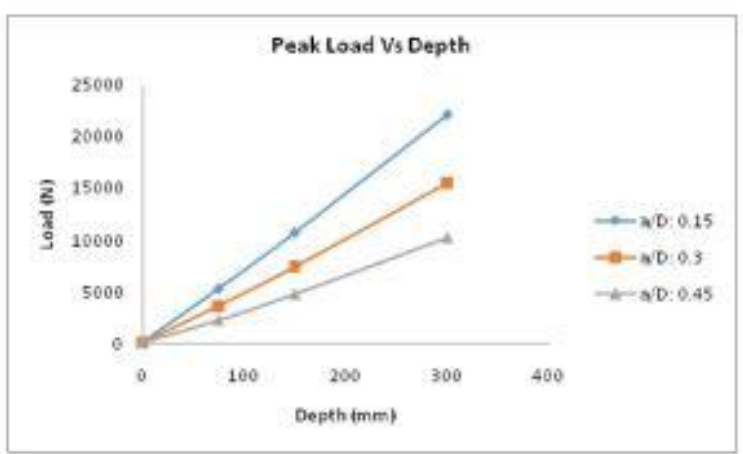

Figure 29. Peak Load Vs Depth (M30 Concrete) 


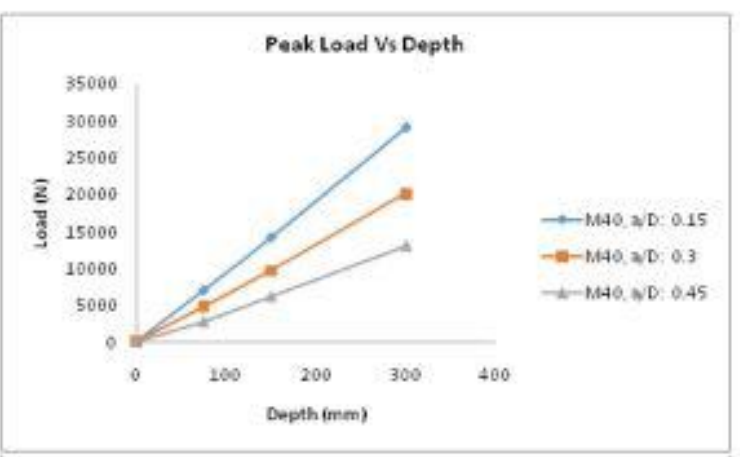

Figure 30. Peak Load Vs Depth (M40 Concrete)

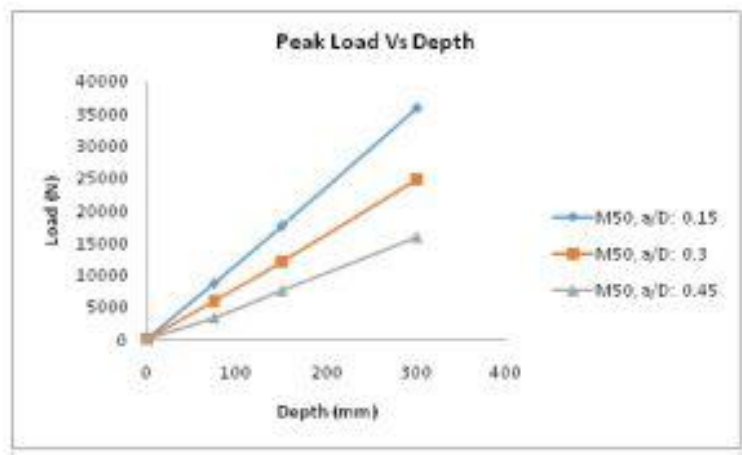

Figure 31. Peak Load Vs Depth (M50 Concrete)

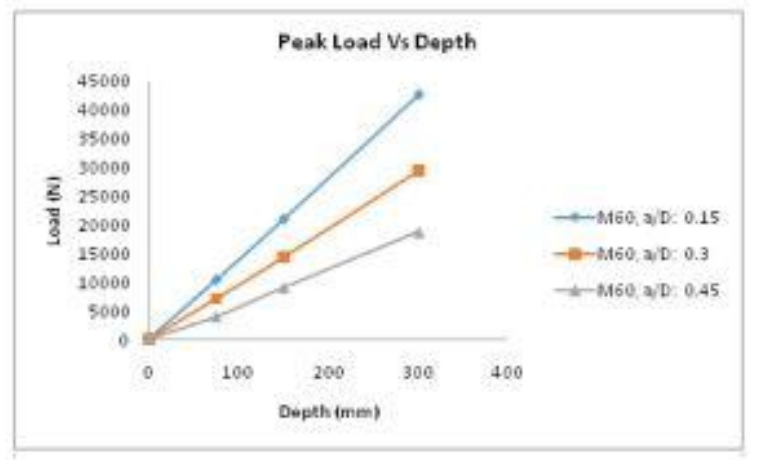

Figure 32. Peak Load Vs Depth (M60 Concrete)

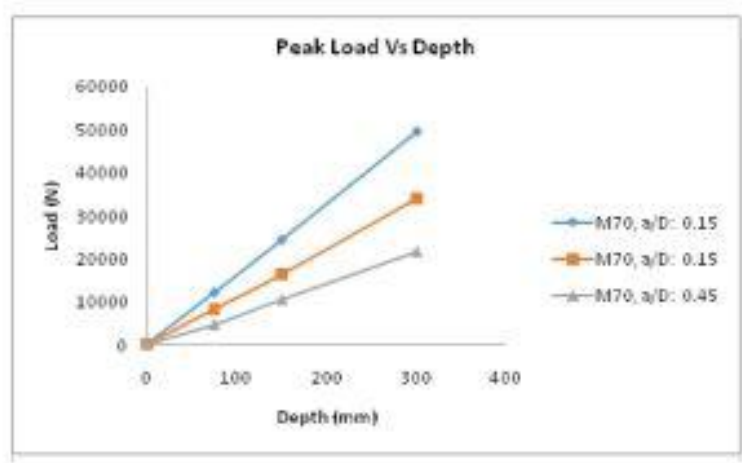

Figure 33. Peak Load Vs Depth (M70 Concrete)

\section{E. Peak Load Vs SINT (Grade Wise)}

In a particular size of the beam and for a particular notch depth ratio, the stress intensity factor is observed to be increasing with the increase in the grade of the concrete. This is due to the increased load resisting capacity of the beam with the increase in the grade of concrete.

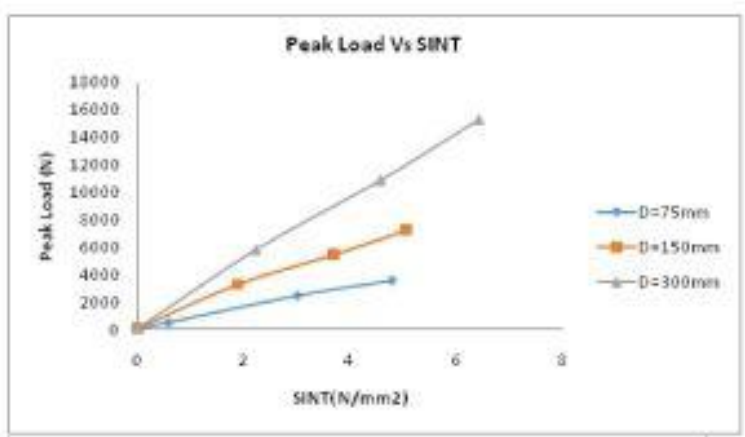

Figure 34. Peak Load vs SINT (M20 Concrete, a/D: 0.15, 0.3, and 0.45)

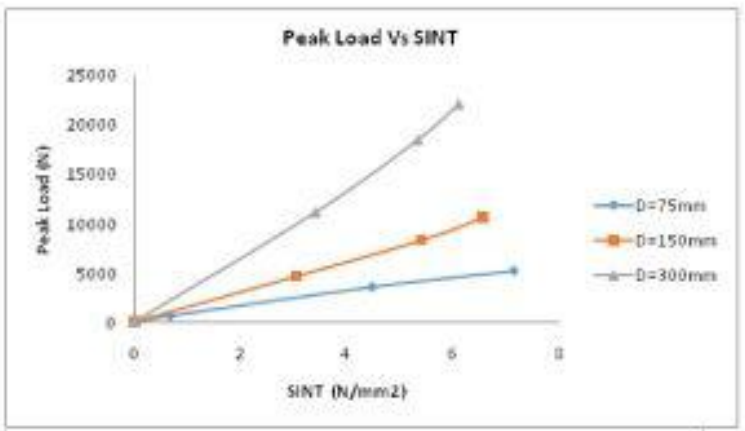

Figure 35. Peak Load vs SINT (M30 Concrete, a/D:0.15, 0.3, and 0.45)

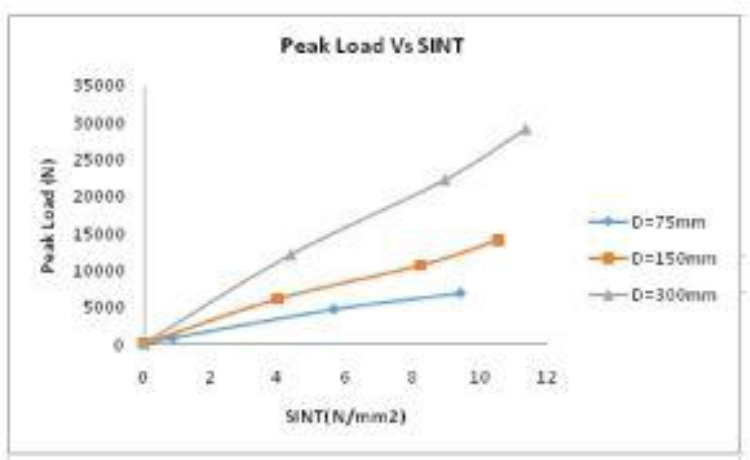

Figure 36. Peak Load vs SINT (M40 Concrete,a/D: $0.15,0.3$, and 0.45 ) 


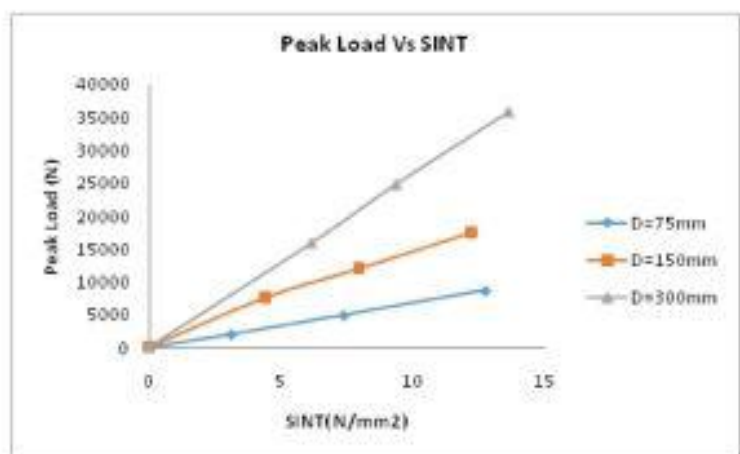

Figure 37. Peak Load vs SINT (M50 Concrete, a/D: 0.15, 0.3, and 0.45)

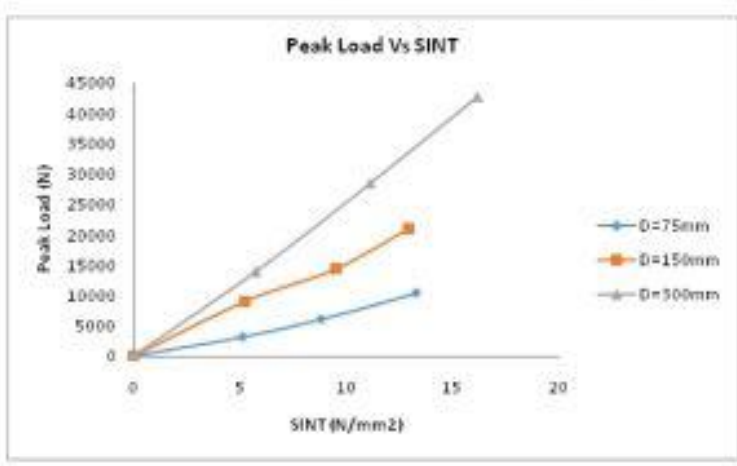

Figure 38, Peak Load vs SINT (M60 Concrete, a/D:0.15, 0.3, and 0.45)

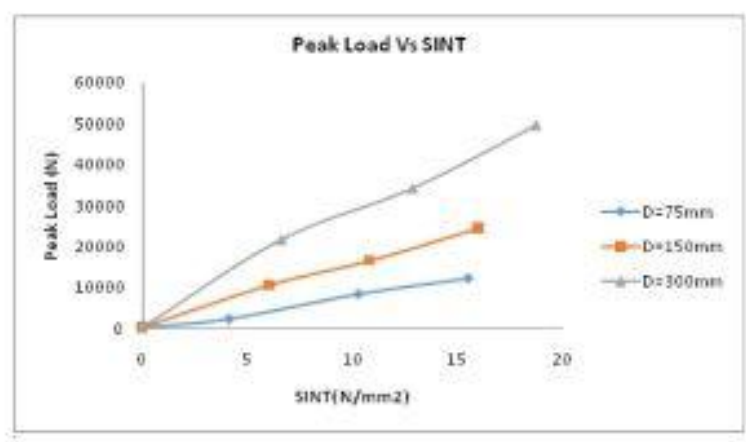

Figure 39. Peak Load vs SINT (M70 Conerete, a/D:0.15, 0.3, and 0.45)

\section{F. Fracture Toughmess Vs $a_{0}$}

Fracture Toughness is found to be decreasing with an increasing the notch depth ratio. Increase in the notch depth ratio $(\mathrm{a} / \mathrm{D})$ increases the brittleness of the member. In other words, increase crack length in a beam it behaves in a brittle manner.
TABLE IV

FRACTURE TOUGHNESS FOR BEAMS OF DIFFERENT SIZES, GRADES AND NOTCH DEPTH RATHOS

\begin{tabular}{|c|c|c|c|}
\hline $\begin{array}{l}\text { Grade of } \\
\text { concrete }\end{array}$ & $\begin{array}{l}\text { Size of Beam } \\
(\mathrm{mm} \times \mathrm{mm})\end{array}$ & $a / D$ & $\begin{array}{c}\text { Fracture } \\
\text { Toughness } \\
\left(K_{1}\right)\end{array}$ \\
\hline \multirow{9}{*}{$\mathrm{M} 20$} & \multirow{3}{*}{$100 \times 75$} & 0.15 & 1630.551 \\
\hline & & 0.3 & 1172.099 \\
\hline & & 0.45 & 224.4949 \\
\hline & \multirow{3}{*}{$100 \times 150$} & 0.15 & 3041.527 \\
\hline & & 0.3 & 2004.835 \\
\hline & & 0.45 & 1628.77 \\
\hline & \multirow{3}{*}{$100 \times 300$} & 0.15 & 5964.461 \\
\hline & & 0.3 & 4421.192 \\
\hline & & 0.45 & 2908.368 \\
\hline \multirow{9}{*}{ M 30} & \multirow{3}{*}{$100 \times 75$} & 0.15 & 2188.163 \\
\hline & & 0.3 & 1715.451 \\
\hline & & 0.45 & 307.7274 \\
\hline & \multirow{3}{*}{$100 \times 150$} & 0.15 & 4443.351 \\
\hline & & 0.3 & 3238.135 \\
\hline & & 0.45 & 2152.639 \\
\hline & \multirow{3}{*}{$100 \times 300$} & 0.15 & 8597.053 \\
\hline & & 0.3 & 5918.291 \\
\hline & & 0.45 & 4051.29 \\
\hline \multirow{9}{*}{$\mathrm{M} 40$} & \multirow{3}{*}{$100 \times 75$} & 0.15 & 2993.999 \\
\hline & & 0.3 & 2254.136 \\
\hline & & 0.45 & 403.6956 \\
\hline & \multirow{3}{*}{$100 \times 150$} & 0.15 & 6038.525 \\
\hline & & 0.3 & 4310.684 \\
\hline & & 0.45 & 2770.805 \\
\hline & \multirow{3}{*}{$100 \times 300$} & 0.15 & 10684.07 \\
\hline & & 0.3 & 7665.504 \\
\hline & & 0.45 & 6027.837 \\
\hline
\end{tabular}

\begin{tabular}{|c|c|c|c|}
\hline $\begin{array}{l}\text { Grade of } \\
\text { concrete }\end{array}$ & $\begin{array}{l}\text { Size of Beam } \\
(\mathrm{mm} \times \mathrm{mm})\end{array}$ & a/D & $\begin{array}{c}\text { Fracture } \\
\text { Energy }\left(\mathrm{G}_{\mathrm{l}}\right) \\
\mathrm{N}-\mathrm{mm}\end{array}$ \\
\hline \multirow{9}{*}{ M50 } & \multirow{3}{*}{$100 \times 75$} & 0.15 & 3903.577 \\
\hline & & 0.3 & 2756.153 \\
\hline & & 0.45 & 508.0138 \\
\hline & \multirow{3}{*}{$100 \times 150$} & 0.15 & 7780.419 \\
\hline & & 0.3 & 5166.345 \\
\hline & & 0.45 & 3434.419 \\
\hline & \multirow{3}{*}{$100 \times 300$} & 0.15 & 13921.14 \\
\hline & & 0.3 & 10116.19 \\
\hline & & 0.45 & 6792.45 \\
\hline \multirow{9}{*}{ M60 } & \multirow{3}{*}{$100 \times 75$} & 0.15 & 4643.469 \\
\hline & & 0.3 & 3298.596 \\
\hline & & 0.45 & 579.1644 \\
\hline & \multirow{3}{*}{$100 \times 150$} & 0.15 & 8571.443 \\
\hline & & 0.3 & 6167.214 \\
\hline & & 0.45 & 4401.905 \\
\hline & \multirow{3}{*}{$100 \times 300$} & 0.15 & 16608.7 \\
\hline & & 0.3 & 11969.52 \\
\hline & & 0.45 & 8031.691 \\
\hline \multirow{9}{*}{ M70 } & \multirow{3}{*}{$100 \times 75$} & 0.15 & 5410.337 \\
\hline & & 0.3 & 3991.962 \\
\hline & & 0.45 & 667.9269 \\
\hline & \multirow{3}{*}{$100 \times 150$} & 0.15 & 9974.348 \\
\hline & & 0.3 & 7046.427 \\
\hline & & 0.45 & 4737.552 \\
\hline & \multirow{3}{*}{$100 \times 300$} & 0.15 & 19274.71 \\
\hline & & 0.3 & 14798.95 \\
\hline & & 0.45 & 9306.139 \\
\hline
\end{tabular}




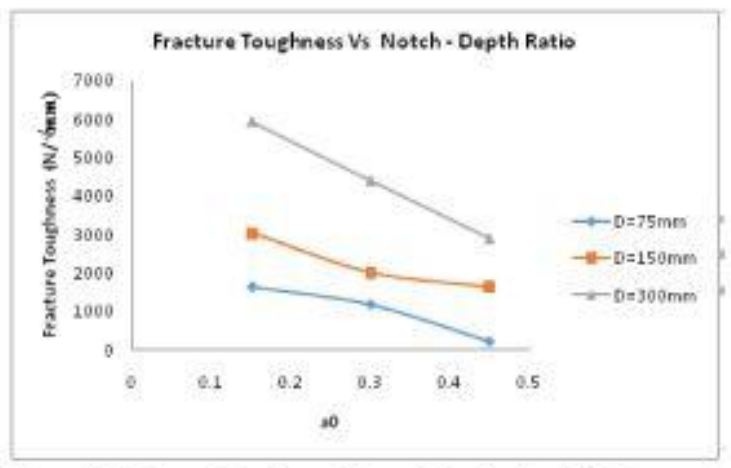

Figure 40. Fracture Toughness Vs notch-depth ratio (M20 Concrete)

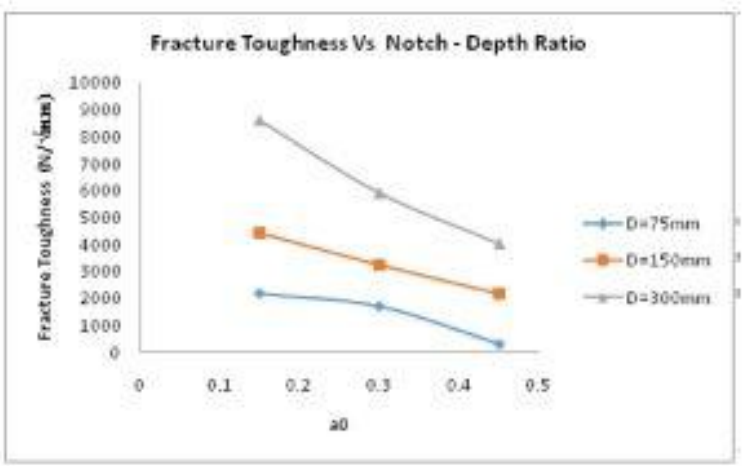

Figure 41. Fracture Toughness Vs notch-depth ratio (M30 Concrete)

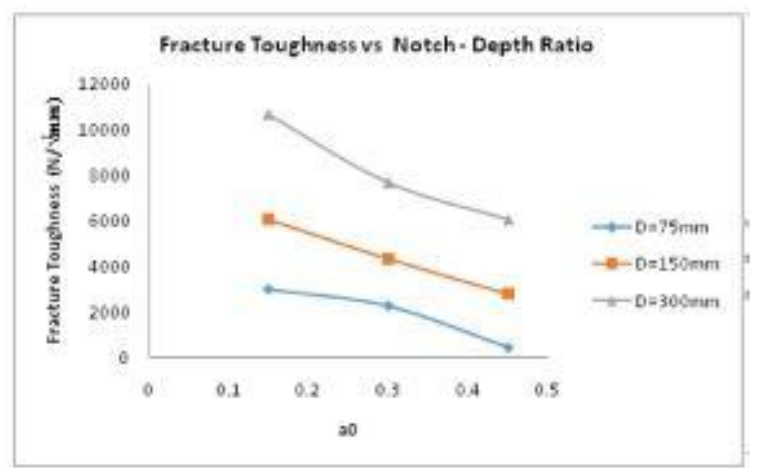

Figure 42. Fracture Toughness Vs notch-depth ratio (M40 Concrete)

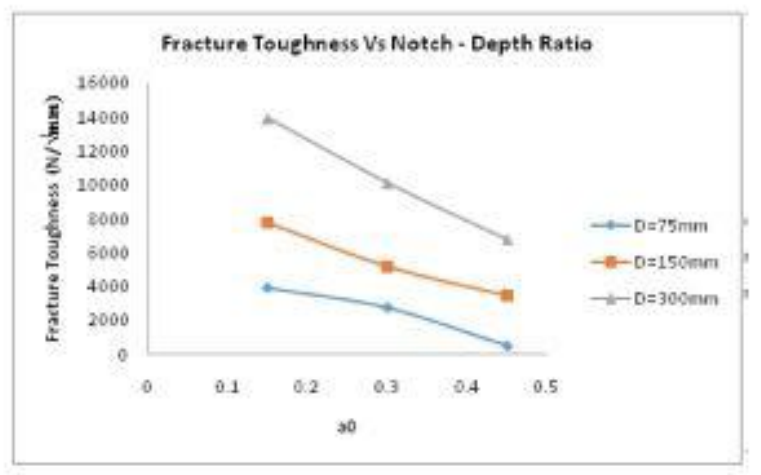

Figure 43. Fracture Toughness V's notch-depth ratio (M50 Concrete)

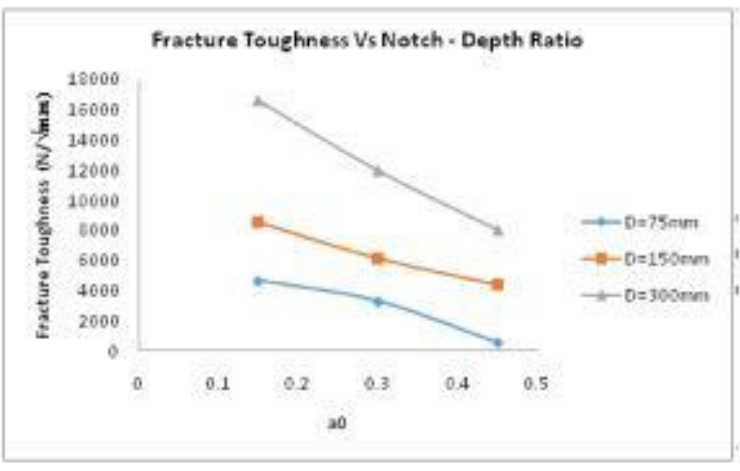

Figure 44. Fracture Toughness Vs notch-depth ratio (M60 Concrete)

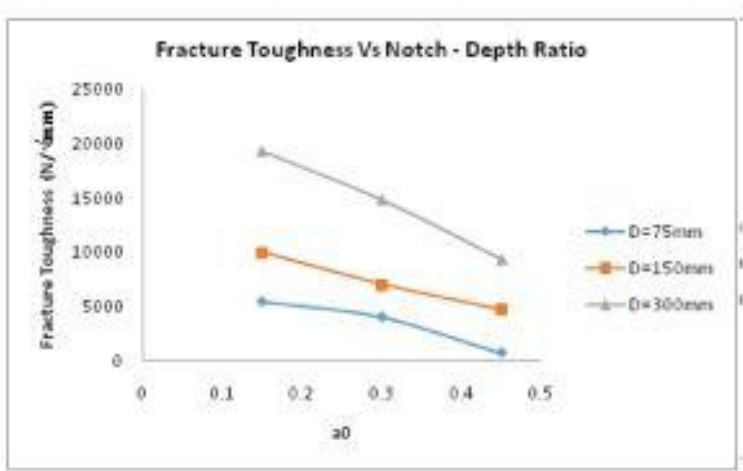

Figure 45. Fracture Toughness Vs notch-depth ratio (M70 Concrete)

\section{Conclusions}

The fracture behavior of the notched plain concrete beams of different sizes and notch depth ratios for different grades of concrete has been analyzed based on the modelling of beams in ANSYS. The variation of fracture parameters has been studied and presented below.

1. In a particular size of the beam and for a particular notch depth ratio, the fracture energy and fracture toughness are observed to be increasing with the increase in the grade of the concrete. This is due to the increase in the depth of uncracked ligament which has enhanced the load resisting capacity. Hence, the fracture energy of the larger depth beams. Same trend was observed with the increase in the notch depth ratios.

2. In a particular grade of concrete and for a particular size of the beam, the fracture energy and fracture toughness are observed to be decreasing with increase in the notch depth ratios. This is due to the decrease in the depth of uncracked ligament. Same trend was observed with the increase in the size of the beams.

3. When the grade of concrete and the size of the beam is constant, then the peak load and the deflection were found to be decreasing with the increase in the notch depth ratios. This is due to the increase in the brittleness of the member. In other words, the increase in the crack length in a member makes it to behave in a brittle manner.

4. In a particular size of the beam and for a particular notch depth ratio, the stress intensity factor is observed to be increasing with the increase in the grade of the concrete. 
This is due to the increased load resisting capacity of the beam with the increase in the grade of concrete.

5. In a particular size of the beam and for a particular notch depth ratio, the peak deflection value is observed to be increasing with the increase in the grade of the concrete. This is due to the increased load resisting capacity of the beam with the increase in the grade of concrete.

6. Increase in the notch ratio (a/D) increases the brittleness of the member. In other words, increase in crack length in a structure pushes the structure to behave in a brittle manner.

7. It indicates that the increase in notch depth ratio decreases the fracture energy. In other words, increase in crack length of a structure requires less fracture energy for extending the crack. A decrease in fracture energy for crack extension indicates the brittleness of the structure.

\section{REFERENCES}

[1] P. Subba Rao, A. Venkateshwara Rao, "A study on loaddeflection behavior of cracked concrete beam using FEM": fracture mechanics approach, International Journal of Engineering Research \& Technology, ISSN: 2278 - 0181 . Vol. 1 Issue 6, August - 2012.

[2] T. Muralidhara Rao, T.D.Gunneswara Rao, "Size effect of plain concrete beams-an experimental study". International Journal of Research in Engineering \& Technology, ISSN: 2319 - 1163, Vol. 02 Issue 06, June - 2013.

[3] H. Ananthan, B.K. Raghuprasad, K.T. Sundara Raja Iyengar, "Influence of strain softening on the fracture of plain concrete beams", International Joumal of Fracture 45: 195 219, 1990. Received 20 August 1988; accepted in received from 7 June 1989

[4] B.K.Raghu Prasad, Rabindra Kumar Saha, A.R.Gopalakrishnan., "Fracture behavior of plain concrete beams - experimental verification of one parameter model", ICCES, Vol.14, No.3, pp.65-83.

[5] B.K. Raghu Prasad, T.V.R.L. Rao, A.R.Gopalakrishnan, "Modified lattice model for mode-i fracture analysis of notched plain concrete beam using probabilistic": ICCES, Vol.6, No. 2, pp.99-112.

[6] Prashanth M. H., Parvinder Singh, J. M. Chandra Kishen. "Fatigue crack propagation in plain concrete beams by acoustic emission technique", $g^{\text {fh }}$ International conference on Fracture Mechanics of Concrete and Concrete StructuresFraMCo - 9, DOI 10.21012/FC9.069.

[7] Rajkumar, K and Vasumathi.A.M., "Study on the flexural behavior of concrete beam with two point loading", International Joumal of Earth Science and Engineering. April 2013, P.P.21-27.

[8] Desayi P., Krishnan S.,"Equation for the Stress-Strain Curve of Concrete", Journal of the American Concrete Institute, 61, pp. 345-350, March 1964.

[9] "Prabhakara R., Muthu K.U., Meenakshi R, "Investigation on ultimate flexural strength and ductility behavior of HSC beams", Indian Concrete Journal, Oct 2006, pp.40-50.

[10]F.P.Zhou, R.V.Balendran, A.P.Jeary, "Size effect on flexural, splitting tensile and Torsional strengths of High Strength concrete", Cementand ConcreteResearch, Vol.28, No.12,pp.1725-1736,1998. 